\title{
Editorial
}

\section{Should place brands be simple?}

\author{
Place Branding and Public Diplomacy (2009) 5, 91-96. doi:10.1057/pb.2009.6
}

There is a basic question about the images of places which has seldom been addressed in the literature, and which remains largely unresolved: do places benefit more from having a clear, simple image, or is it preferable for them to have a rich, complex and even contradictory image? Societies are intrinsically complex and contradictory phenomena, so why attempt to alter or disguise this fact in the way they represent themselves and are perceived by outsiders?

The question leads to some fundamental issues about the theory and practice of place branding; indeed, it challenges the very idea of applying brand theory to the development of places.

Brands in the commercial sphere tend to opt unequivocally for projecting a clear and simple image. Of course, any corporation that is lucky and successful enough to have maintained its brand for generations may find that the brand image, over time, becomes richer and more complex; but branding is essentially seen as a process of reduction. The laser-like clarity of a single, distinctive positioning is often described as the product's only chance of cutting through the indifference of the consumer, the chaos of the marketplace and the clutter of the media. For decades, commercial brands have followed the prevailing wisdom and sought to reduce their 'essence' down to a single promise to the consumer.

This author has argued that places are exactly the opposite, and that this is one of the main reasons why commercial branding practice doesn't apply in any straightforward way to their management or promotion: good sense suggests, and research tends to confirm, that richness and complexity are valuable image attributes for any country, city or region. This is primarily because the image must be able to embrace and support the wide variety of industrial, cultural and political activity which countries and cities are likely to engage in. It's difficult to imagine any single 'positioning' for a country which could span all the activities of its private and public sectors, without being so bland and generic as to be useless as a distinguishing narrative.

Equally, the external 'audience' of the country, whether considered as tourists, investors, business visitors, allies, consumers of its exports, immigrants or participants in cultural exchange, must be able to find a 'promise' that matches their engagement with the country, irrespective of their own cultural viewpoint and their own sectoral interest, and at any point in time. The idea of a single promise that can embrace such a wide variety of product offerings and consumer needs seems almost absurd.

Moreover, a rich and nuanced national image acts as an insurance policy against failure or a negative consumer experience of some aspect of the country, its people or its products: this, for example, is why America's image incorporates deeply unpopular foreign policy alongside muchloved popular culture and products, and is still held in overall high esteem by many publics abroad. 
However, building richness and complexity into a national image is a daunting task. The fact is that most people in most countries aren't even very interested in their own country, let alone the 200 or so other countries around the world. They are interested in their own lives, their own families, their own neighbourhood. Perhaps they sometimes think about America or China or Iraq or some other country that's regularly in the news. Perhaps they occasionally give a thought to their neighbouring countries, to another country where friends or relatives live, or to a country they would like to visit one day as tourists or migrant workers or students. But the idea that large numbers of people around the world would spend time thinking about countries which have no real relevance to their daily lives is a vain and idle fantasy, and spending taxpayers' money trying to force them to do so is utterly unjustifiable.

Acquiring a rich, tolerant, nuanced and complete perception of another country takes time, and requires a certain commitment on the part of the perceiver: she or he has to learn the country, and this surely cannot take place in a passive way, simply as a consequence of the 'single shot' of conventional marketing and branding techniques. The visitor, investor or consumer has to want to learn about a place in order to arrive at a fuller and richer understanding of it. Taken in its most literal sense, the need to learn the country is the reason why working on national image through educational support programmes in foreign schools is often so effective: children who study another country at school are likely to retain a positive bias for that country which could last a lifetime.

It was in an effort to resolve this dilemma of simplicity and richness that this author proposed the idea of nation brand as signpost:

The definition of brand as shorthand or signpost for value, or quality, or equity, is a useful one: in other words, you don't attempt to pack all meaning into a single proposition or slogan, or jump the gun on the time it takes for a consumer to "learn" the complex product, but be content with a sign which can stand for, and later refer accurately back to, the whole experience, once it is more familiar to the consumer. One has to have the wisdom and patience to accept that this sign will not be wholly meaningful to the consumer at the start, but it is a vessel which will become more and more replete with meaning as meaning is absorbed.

Simplification has a tendency to reduce appeal, since so much of the ultimate appeal of a country is its richness and complexity. The true art of branding is distillation: the art of extracting the concentrated essence of something complex, so that its complexity can always be extracted back out of the distillate, but it remains portable and easily memorable. The distillate, rather than actually attempting to contain all the detail of the country in question, is simply the common thread, the genetic constant, which underlies the basic commonality between the different parts of the brand. (Anholt, 2001)

It is typical for less well-known countries trying to establish an international profile that they will start with a signpost brand of this sort: it is the sharp point of their image which enables them to penetrate consumer consciousness and add their country's name to the list of candidate countries in the consumer's mind. Indeed, there is probably some close equivalent in place branding of the classic marketing notion of the 'evoked set', a theory which argues that prospective purchasers never hold a shortlist of more than a small number of items in consideration at any one time. It would be a worthwhile research project to try and determine whether the evoked set theory does indeed hold true for places - as tourist destinations, business travel destinations, investment locations, and even as political allies, cultural partners and country of origin for products and services. If so, the implications are striking: for any country to stand a chance of being selected in one of these categories, it is not enough for them to improve their image: they need to force their way into the evoked set. 
Such countries, having used a deliberately simplified brand promise to establish their presence in the evoked set and register in the consciousness of the audience, can then gradually proceed to a widening of the discourse and a more nuanced 'conversation' with their multiple target groups.

Better-known countries, on the other hand, might already be within the evoked set and have little interest in developing a single 'promise' (and little chance of doing so without compromising the significance and breadth of their image and identity), but will want to invest more in the activities that typically widen and deepen existing awareness of their full offering: cultural relations, educational activities and exchanges, cultural tourism and so on.

Some countries might be faced with the need to sharpen and broaden their image at the same time for different publics or in different sectors, as economic patterns change. Wealthy, developed European nations, for example, may need to broaden and enrich their profiles within Europe and North America, but find that they are much less well-known in their emerging target markets of China, India, Russia and Brazil, where the task is basically one of introducing the brand; and a simpler, single promise is then far more appropriate.

In all cases, this kind of reductive, signpost branding should only be considered as a temporary measure, designed to get a country to register on the radar of indifferent or ignorant audiences. Such a brand is comparable to the point of an ice-axe, the purpose of which is to achieve traction on the steep ice-face of people's limited attention and interest in other countries. As soon as feasible, the relationship must be broadened, and marketing or selling must give way to teaching and discussing; projection must give way to engagement; monologue must be replaced by dialogue. But no dialogue is possible without first creating the desire for that dialogue in the interlocutor.

Moving away as soon as possible from the signpost phase of place branding is essential not least because there are real dangers associated with the attempt to 'whet' a country's identity into a single-minded, potent and functioning brand with international reach. Such an exercise, as this author has often argued, runs the risk of devaluing the essential dignity of places; of diminishing the diversity of culture, race, history and activities of the place; of creating an undesirable level of Foucaultian governmentality (Foucalt, 1978-1979) ${ }^{1}$; of excluding certain sectors of business or community from the benefit of the positive image; and of holding the country hostage to a narrow promise that later circumstances might invalidate. In many ways, this kind of branding is the conceptual opposite of democracy; it is also extremely risky.

Indeed, in the longer term, the deliberate branding of places looks more like a problem than a solution. 'Branding' in this sense is what public opinion does, reducing the richness of the nation (richness being a component of its essential dignity) to the level of a naive shorthand. It is not what governments should deliberately try to do, 'playing to the gallery' and pandering to the ignorance of public opinion. What responsible governments ought to do is enrich and improve, or at least maintain and protect, the nation's good name, that most valuable national asset with which they have been entrusted for the term of their office.

The argument that good place images are rich and complex has usually been espoused, even if not expressed in quite these terms, by the proponents and practitioners of cultural relations, both in the context of national image building and bilateral relationship building. The experience of countries that have successfully practised cultural relations over many years shows that consistent, mutual cultural exchange does eventually create an environment where respect and tolerance flourish, and this undoubtedly also favours increased trade in skills, knowledge, products, capital and people. People who understand each other tend to get on better, and people who get on better tend to trade with each other more frequently, more freely and with greater mutual profit. 
The real challenge is opening the door to dialogue in the first place. Overcoming the essential lack of interest in a foreign country may in some cases be a matter of disrupting the audience's indifference, prejudice or expectations. The problem faced by most countries is not that they lack good things to say about themselves, or even that they don't say or do good things often enough: it's usually that people just aren't paying attention, and don't see why they should.

This is the main reason why this author has so often insisted on the inappropriateness of marketing communications for enhancing, creating or altering national image. Such forms of advertising work, and are acceptable, when one is offering something that is for sale to people who are, at least potentially, interested in what one is selling. In place branding one is promoting something that isn't for sale, to people who are almost certainly not interested. Under such circumstances, the whole panoply of marketing communications is fatally compromised.

Governments that want to 'brand' their countries should therefore not ask the question 'what can we say to make our country famous?', but 'what can we do to make our country relevant?' Instead of asking how they can charm or coerce people into admiring their country, they should ask themselves why people in other countries should even think about their country in the first place. And if there honestly is no good reason why people should think about that country, and if a good reason can't be created, then the idea of nation branding should simply be dropped, and the government should accept that their destiny, at least for the time being, is not to be famous or admired outside their own neighbourhood or region, just quietly effective. And in many cases, there may be nothing wrong with having a low profile: being a 'famous country' is no sort of panacea.

Making the country relevant to the audience involves a number of notions that are all too often left out of the place branding discourse. The first of these - which incidentally happens to be one of the basic rules of marketing - is to based one's strategy on a clear analysis of the perceptions, needs, habits and aspirations of one's target audience; indeed, to treat this as a more important consideration than the product offering itself. It is rare indeed that governmental place branding teams look anywhere except inwards, and they frequently end up simply describing the place, repeating long and carefully prepared lists of its attributes and achievements. This is classic bad marketing, as it provides no 'reason to buy', and by failing to demonstrate any understanding of the target audience, creates no empathy or sympathy with them, and fails to open a dialogue.

Another classic error of place branding is the failure to offer the target audience anything in return for its attention; again, this is classic bad marketing, as it makes the fundamental error of assuming that the consumer is as interested in the product as its producer is.

Part of the reason why cultural relations is one of the few demonstrably effective forms of place branding is because it offers some pleasure in return for the consumer's attention: by proposing artistic or intellectual stimulation, the country both delights its audience and pays in advance for the respect and interest of that audience. Bearing cultural gifts in this way gives pleasure to the recipient, and at the same time burnishes the reputation of the giver.

So powerful and so effective is this kind of transaction, many countries increasingly now recognise that these exercises of 'soft power' are anything but soft. The benefits are measurable, tangible and considerably more cost-effective than coercion. There is, currently, an explosion in the quantity of art and culture being exhibited and consumed around the world, and although it is hard to measure, the increase might just as well be supply-driven as demanddriven: rather than revealing a gratifying increase in the cultural appetites and sensibilities of populations, it may simply demonstrate how many governments are beginning to realise the tremendous power of cultural diplomacy for achieving their foreign policy objectives via the 
general population, rather than via official government channels.

Yet many people, perhaps in particular those who revere 'traditional' diplomacy, are keenly sceptical about the whole notion of national image. Michel Girard makes a cogent argument against this modern preoccupation:

... when one is overly possessed by communication of images, all productive energy and attention is being channelled outside the substance of the problem one is meant to solve. In negotiation, it is quite often helpful to exercise some discretion, even outright confidentiality, as political matters cannot be pushed towards quick solutions. To mediate successfully, there must be a third party role - one possessing the ability to maintain a front of temporary secrecy for the sake of the antagonists' building of trust through stating sincere positions and facilitating realistic bargaining and so on. But when the third party is running for popularity concurrently with keeping the negotiations onboard, diplomatic and media purposes will cross. The result is a kind of soft and anodyne diplomacy. In other words, a diplomacy which does not want to hurt anybody, and tries only to multiply opportunities to improve one's image. (Girard, 1999)

This observation cuts right to the heart of the question of place image, and yet seems to miss a fundamental point. To characterise all 'branding' or 'public relations' or 'advertising' (terms which Girard uses more or less interchangeably) as inherently deceptive practices, unfailingly borne of a desire to manipulate the perceptions of the public, is facile, and curtails what should be a longer and more profound enquiry. Not all governments use communications in order to lay claim to motivations which are different from their real ones, and desiring a particular image for one's country isn't necessarily incompatible with doing things for the 'right' reasons. Nothing could be more natural than to desire that one's country enjoys the reputation it deserves; to ensure that it deserves it; and to ensure that it enjoys it.
The best possible reason for wishing to present a particular national image is that it is both fair and true; the desire is simply to be properly understood, rather than allow one's country to remain forever the victim of an outof-date cliché, truly 'branded' by public ignorance. The experience from this author's own practice is that very many governments, far from trying to present an idealised or invented 'brand' for themselves, are in fact trying to shed the 'brand' which public opinion, or public ignorance, has foisted on them.

Some would claim, this author included, that hoodwinking international public opinion is, in any case, almost impossible, since no government begins to exercise any meaningful influence over the multiple channels of communication that publics have access to. As I have often said, one of the benign effects of the globalisation of media is that it has rendered propaganda anachronistic, a virtual impossibility.

Far from being incompatible, the art of good branding and the art of good leadership are, at heart, indistinguishable, as both are fundamentally concerned with being true to one's core values. Branding teaches the importance of having a set of firm beliefs and values, a clarity of purpose which unfailingly drives one's decisions; in other words, integrity. Branding, at its best, is a technique for achieving integrity, and reaping the reputational benefits of integrity.

The importance of clarity, interestingly, was raised by another speaker at the same conference where Girard made the observations quoted above. Quentin Peel, a journalist, said the following:

Margaret Thatcher had a clear line. John Major had a total muddle. A tremendous amount of spin-doctoring went on to try and put some clarity in this muddle, but in the end nobody wanted to know because his policies were a complete confusion. So, whether you liked the policies or not she had a policy and it was saleable and people wanted to hear it. He had confusion and in the end they just walked away. The lesson of all this is that 
it is not worth telling the public if you have a bad policy or a muddled policy. Have a clear policy and then you do not have to sell it in the end.

(Peel, 1999)

Although Peel is unsurprisingly suspicious of the use of public relations by governments to push a particular line to the media, he acknowledges that what really matters to the media, and consequently to public opinion, is clarity; and clarity is precisely what any good brand strategy will attempt to deliver.

What if brand management were ultimately all about developing clear policies that clearly resonate with one's fundamental values and beliefs? What if branding were more about being truthful than being mendacious? What if branding were more about good governance and good leadership than presentation or rhetoric? What if branding were more about learning how to be true to oneself than how to lie to other people?

Some might think that the espousal of branding techniques by governments is a symptom of weakness and dishonesty, a sign that the government is driven by public opinion, but in fact it can be, and should be, exactly the opposite: it's a sign that the government desires the country and its policies to be driven by its true identity. It's the lack of a set of core principles and identity which creates poor and muddled policies and poor reputation. Inner certainty creates good policies, clear behaviour and a good reputation.

The way in which the images of places is formed can be expressed by the simple model:

$$
\text { IDENTITY - BEHAVIOUR - IMAGE }
$$

Who you are determines how you behave; how you behave determines how you are perceived. Place branding, when properly understood, is a system that respects the power of integrity above all else, and recognises that only perfect integrity can sway public opinion.

\section{NOTE}

1 The author is indebted to Sienna SmaleJackson at the University of Otago for pointing out the link between Foucault and place branding.

\section{REFERENCES}

Anholt, S. (2001) Brand New Justice. London: Palgrave Macmillan.

Foucault, M. (1978-1979) Naissance de la biopolitique: Cours au Collège de France. Paris: Gallimard \& Seuil.

Girard, M. (1999) States, diplomacy and image-making - What is new? In: A. Chong and J. Valencic (eds.) The Image, the State and International Relations. London: LSE.

Peel, Q. (1999) An ideal image - A journalist's view. In: Chong and Valencic (eds.) The Image, the State and International Relations. London: LSE.
Simon Anholt

Editor 